\title{
EDITORIAL
}

\section{As Especialidades Médicas no Brasil}

$\mathrm{E}^{n}$ m 1997 o Conselho Federal de Medicina (CFM), a Associação Médica Brasileira (AMB), a Federação Nacional dos Médicos (FENAM) e a Comissão Nacional de Residência Médica (CNRM) constituíram uma Comissão Mista para a uniformização de critérios para o reconhecimento das especialidades, uma vez que os da CNRM divergem dos da AMB e CFM.

No Brasil, as Sociedades de Especialidade (SE) emitem os Títulos de Especialista (TE) no Brasil, como faz a Sociedade Brasileira de Medicina Legal (SBML) há quase 30 anos; com o estabelecimento do convênio entre a AMB e o CFM, em 1989, estes passaram a dar o seu reconhecimento aos títulos emitidos pelas SE. A CNRM, entretanto, só reconhecia como especialidade médica a que tinha processo de formação através de Residência Médica, daí a necessidade de uniformização de critérios.

A Comissão Mista reuniu-se em 10/09/1997 visando, entre outros assuntos em pauta, a caracterização das especialidades médicas e de suas áreas de atuação. O conceito de especialidade médica foi então assim definido: "campo restrito da medicina que se aprofunda verticalmente através de conhecimentos específicos, senso-percepções, atitudes e habilidades necessárias para uma determinada prática médica, com abordagem das dimensões bio-psicosociais do indivíduo". Área de atuação foi caracterizada como "modalidade de organização do trabalho médico, que faz parte de uma ou mais especialidades exercida por profissionais capacitados para ações médicas específicas".

Nessa reunião a Medicina Legal foi colocada como área de atuação da Patologia. Em contato que mantivemos com o presidente da Sociedade Brasileira de Patologia foi firmada uma Declaração Conjunta entre esta e a SBML, cuja conclusão foi: - "Em suma, ambas as Sociedades reconhecem que a Patologia e a Medicina Legal são especialidades médicas com objetivos e campos de atuação diversos, não se justificando a inclusão de uma como área de atuação da outra, motivo pelo qual vêm manifestar sua discordância quanto a essa colocação". Novas reuniões se seguiram até que, em 1999, o Ministério da Saúde convocou uma reunião sobre o assunto, uma vez que os países componentes do Mercosul iriam discutir a questão e esse órgão do governo brasileiro tinha que levar uma proposta concreta sobre quais ramos da Medicina deveriam ser eleitos nesses países como especialidades médicas. Ao final, a conclusão foi que o Ministério da Saúde do Brasil defenderia a posição de que seria reconhecida como especialidade médica a que existisse como tal, em pelo menos três dos quatro membros. A Medicina Legal é uma especialidade médica na Argentina, no Uruguai e no Brasil (reconhecida pela AMB e CFM). Desse modo, passou a ser finalmente reconhecida como tal pelo Ministério da Saúde do Brasil e pelos países do Mercosul.

Dessa discussão resta, entretanto, um alerta: a Medicina Legal precisa ser melhor divulgada, principalmente no que tange aos seus campos de atuação. E isto compete a todos os que a exercem.

Daniel Romero Muñoz 